Appl. Ent. Zool. 17 (1) : 119-126 (1982)

\title{
Ovipositional Experience of the Gregarious Parasitoid, Apanteles glomeratus (Hymenoptera : Braconidae), Influencing Her Discrimination of the Host Larvae, Pieris rapae crucivora
}

\author{
Terumi IKAWA \\ Laboratory of Applied Entomology, Faculty of Agriculture, University of Tokyo, \\ Bunkyo-ku, Tokyo 113, Japan \\ Yoshito SuzuKi \\ Department of Biophysics, Faculty of Science, Kyoto University, Sakyo, Kyoto 606, Japan
}

(Received Ạugust 26, 1981)

\begin{abstract}
The gregarious parasitoid, Apanteles glomeratus, oviposits in the larvae of Pieris rapae crucivora. We investigated to find how the previous experiences of the wasp in oviposition influence the degree of host discrimination. The oviposition time and the number of eggs laid in a host had a positive correlationship. Therefore oviposition time was used as an index of the number of eggs laid. The wasp could innately discriminate between the parasitized and unparasitized hosts and laid fewer eggs into the former than into the latter. The more the wasps had oviposited in unparasitized hosts just before encountering the parasitized host, the less number of eggs they laid into the latter; moreover they tended to reject the parasitized hosts. The wasp also reduced the number of eggs laid in an unparasitized host when she oviposited in them successively at short intervals. These results indicate that the wasp could estimate the density of unparasitized hosts by the frequency of oviposition and could control the number of eggs laid. These phenomena were explained by the assumption that the wasp, based on the presumed density of the unparasitized hosts, behaves to maximize her own inclusive fitness throughout her life.
\end{abstract}

\section{INTRODUCTION}

Many parasitic wasps have the ability to discriminate between unparasitized and parasitized hosts and show some degree of restraint in ovipositing in the latter (e.g., SAlt, 1934; Wylie, 1970; Wesloh, 1976). Under conditions where unparasitized hosts are scarce, however, their restraint usually breaks down (SALT, 1961). Lenteren and BAKker (1975) and Lenteren (1976) found that females of the solitary parasitoid, Pseudeucoila bochei, did not avoid parasitized hosts until they had had the experience of ovipositing in unparasitized hosts. From this they concluded that the wasps acquired the ability of host discrimination by learning, and explained the occasional occurrence of superparasitism in that species. But a gregarious parasitoid, Nasonia vitripennis, lays fewer eggs in a parasitized host than in an unparasitiz- 
ed one, though she accepts both of them (Wylie, 1965; Holmes, 1972). Therefore oviposition by wasps in parasitized hosts does not necessarily mean they lack the ability to discriminate between hosts. Furthermore, anothcr explanation can be given for the fact that the degree of host discrimination of wasps varies according to their previous experiences in oviposition; that is, their experiences may induce some information about the future prospects of host finding, and affect their oviposition behavior. Therefore, even though a wasp recognizes a host's parasitization status, she may oviposit in some cases where the density of unparasitized hosts is low, in order to maximize her own inclusive fitness.

In this study, as a first part of a series study, we investigated to find whether the gregarious parasitoid, Apanteles glomeratus, can innately discriminate between parasitized and unparasitized hosts, Pieris rapae crucivora, and how the previous experiences of the wasp influence her host discrimination and regulation of the number of eggs she lays.

\section{MATERIALS AND METHODS}

The hosts. Second instar larvae of Pieris rapae crucivora BoIsDuval were used as hosts, if not otherwise described. They were descendants of adults, pupae, or larvae collected in cruciferous crop fields in Tokyo, Chiba, Kanagawa and Kyoto and fed on Rorripa indica leaves.

The parasitoids. Apanteles glomeratus were obtained from 5th instar larvae of $P$. rapae crucivora collected in cruciferous crop fields in Tokyo, Ghiba and Kanagawa. The adults, both males and females, which emerged on the same day from a mediumsized mass(es) of 20-30 cocoons were maintained in a glass tube $(3 \times 20 \mathrm{~cm})$ at $25^{\circ} \pm$ $2^{\circ} \mathrm{C}$ and 16L: 8D regime of photo cycle. They were fed on sugar and water absorbed on a small piece of cotton. Either of the following wasps were used in each experiment: females which had never oviposited before the test (inexperienced wasps) and those which oviposited in unparasitized host(s) within $1 \mathrm{hr}$ before the test (experienced wasps). The wasps were 4 days after emergence and mated, if not otherwise noted.

Methods. In each test waps were introduced into the small glass tubes $(1.5 \times 9$ $\mathrm{cm}$ ) individually. The host on a small piece of $R$. indica leaf was offered to the wasp with a forceps. All experiments were carried out in the rearing room conditions described above.

Further experimental procedures are described in each section.

\section{RESULTS}

\section{Oviposition times of inexperienced wasps to unparasitized hosts offered successively}

Twelve unparasitized hosts were offered to an inexperienced wasp successively at intervals of $1 \mathrm{~min}$ and each oviposition time was recorded. The oviposition time included the period from ovipositior insertion into the host to its removal. This series was replicated 30 times with 3 - to 7-day-old wasps.

The oviposition time was longest, about $20 \mathrm{sec}$, at the 1st oviposition and decreased gradually until the 4 th oviposition, then stabilizing at about $10 \mathrm{sec}$ (Fig. 1). 


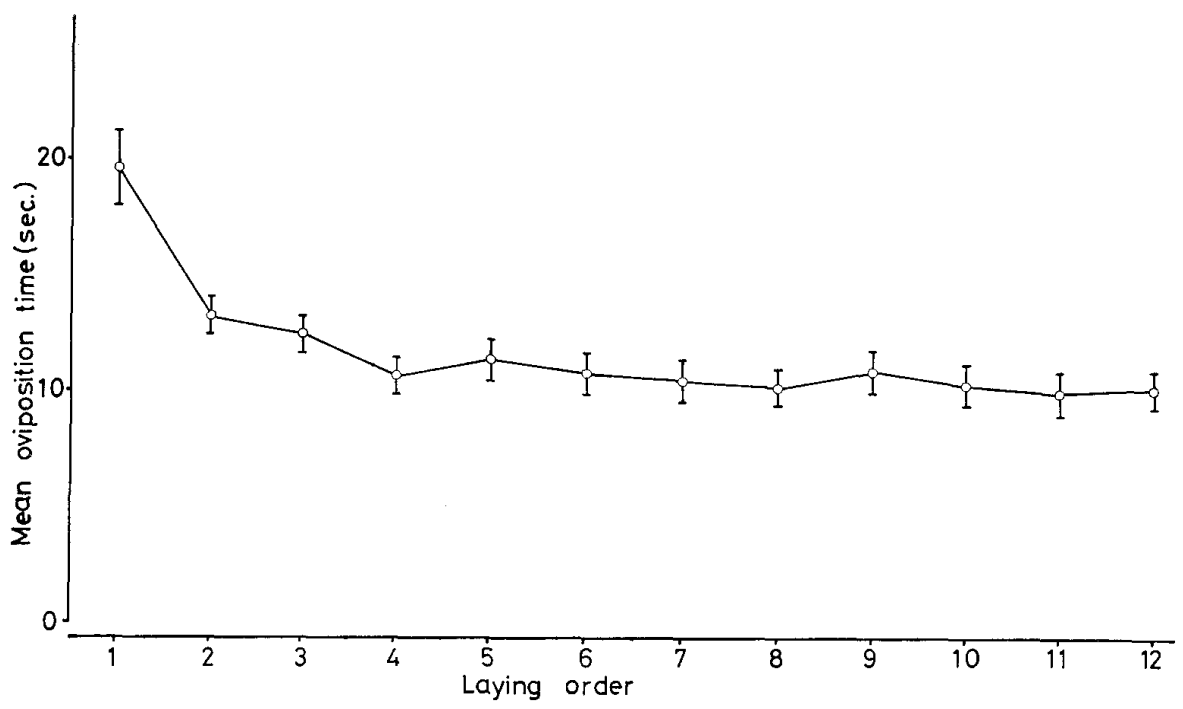

Fig. 1. Oviposition time with $99 \%$ confidence limits of the wasp to unparasitized hosts successively offered.

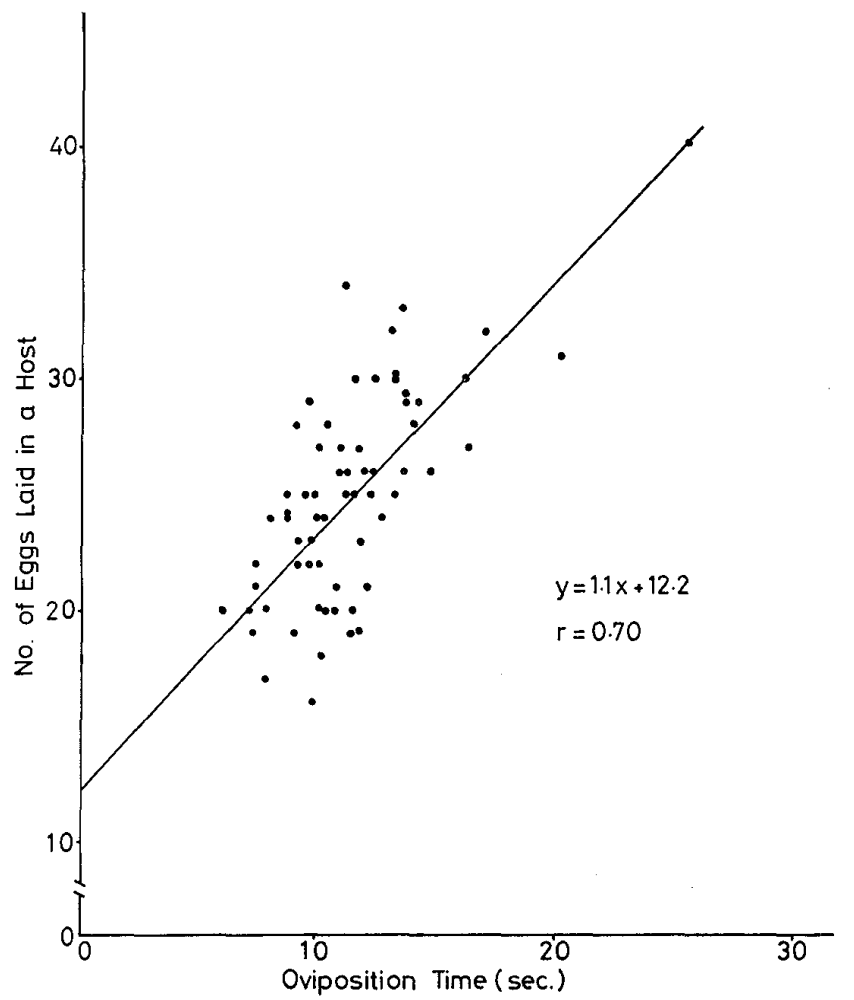

Fig. 2. Correlation between number of eggs laid in a host and oviposition time.

Correlation between the number of eggs laid in a host and oviposition time

From the parasitized hosts obtained in the above experiment 64 were randomly chosen out of the series of 10 which had been parasitized by the 4-day-old wasps. They were dissected under a binocular microscope to count the number of eggs laid in each.

There was a positive correlation between the number of eggs $(y)$ and the ovipo- 
sition time $(x)$, giving the equation, $y=1.1 x+12.2$, with the correlation coefficient $\mathrm{r}=$ 0.70 (Fig. 2). Hereafter the oviposition time was measured instead of counting the number of eggs laid in a host.

\section{Host discrimination by experienced wasps}

Hosts either $30 \mathrm{sec}, 1 \mathrm{~min}, 1 \mathrm{hr}, 6 \mathrm{hr}, 24 \mathrm{hr}$, or $48 \mathrm{hr}$ after parasitization were offered to the experienced wasps. For the control, unparasitized hosts were offered to experienced 4- to 6-day-old wasps. Each test was replicated 20 times.

In Table 1 are shown the mean oviposition times of the wasps to the unparasitized hosts and those parasitized $30 \mathrm{sec}$ to $48 \mathrm{hr}$ before. The time of oviposition to the unparasitized hosts was significantly longer at the $1 \%$ level than that to the parasitized except to those hosts parasitized $30 \mathrm{sec}$ before the test. This shows that the factor(s) preventing the superparasitism had not established itself within $30 \mathrm{sec}$ after the 1st parasitization. But within at least $10 \mathrm{~min}$ the factor(s) was built up, and was still effective after the parasitized hosts moulted to the 3rd instar. Therefore, in the following experiments, hosts which were parasitized more than $10 \mathrm{~min}$ prior were used as the parasitized hosts.

Table 1. Oviposition time of experienced wasps to parasitized and unparasitized hosts

\begin{tabular}{cccc}
\hline $\begin{array}{c}\text { To unparasitized } \\
\text { hosts (sec) }\end{array}$ & $\begin{array}{c}\text { Time interval between } \\
\text { 1st and }\end{array}$ & $\begin{array}{c}\text { To once-parasitized } \\
\text { hosts }(\mathrm{sec})\end{array}$ \\
\hline $14.2 \pm 1.6$ (II) & $30 \mathrm{sec}$ & $13.3 \pm 1.7$ (II) \\
$15.6 \pm 2.6^{\mathrm{a}}$ (II) & $10 \mathrm{~min}$ & $7.8 \pm 1.7^{\mathrm{a}}$ (II) \\
$13.7 \pm 1.8^{\mathrm{b}}$ (II) & $1 \mathrm{hr}$ & $3.5 \pm 2.2^{\mathrm{b}}$ (II) \\
$15.6 \pm 2.6^{\mathrm{c}}$ (II) & $6 \mathrm{hr}$ & $7.1 \pm 1.9^{\mathrm{c}}$ (II) \\
$13.7 \pm 1.8^{\mathrm{d}}$ (II) & $24 \mathrm{hr}$ & $5.1 \pm 2.1^{\mathrm{d}}$ (II) \\
$17.6 \pm 1.8^{\mathrm{e}}$ (II) & $48 \mathrm{hr}$ & $6.4 \pm 2.9^{\mathrm{e}}$ (II $\left.-\mathrm{III}\right) \mathrm{g}$
\end{tabular}

Values are means with $99 \%$ confidence limits.

Roman numerals indicate larval instadia.

a-e Figures with the same letters are significantly different at $1 \%$ level of t-test.

$\mathrm{g}$ This group of hosts was parasitized first at 2 nd instar and second after $48 \mathrm{hr}$ at $3 \mathrm{rd}$ instar.

Host discrimination by inexperienced wasps

An inexperienced wasp was offered three hosts successively at intervals of $1 \mathrm{~min}$ according to the following sequence; 1. $\mathrm{U}(1) \rightarrow \mathrm{P}(2) \rightarrow \mathrm{P}(3), 2 . \mathrm{P}(1) \rightarrow \mathrm{U}(2) \rightarrow \mathrm{P}(3), 3$. $\mathrm{U}(1) \rightarrow \mathrm{U}(2) \rightarrow \mathrm{U}(3)$ (the control series), where $\mathrm{U}$ is the unparasitized host, $\mathrm{P}$ is the parasitized host, and figures in parentheses are the orders of oviposition. Each series was replicated 20 times.

The mean times of oviposition to the parasitized and unparasitized hosts are shown in Fig. 3. In the control series, as in the previous experiment (Fig. 1), the oviposition time decreased gradually from the 1st oviposition to the 3rd. A similar trend was obtained in series 1 , but the times of oviposition to the $\mathrm{P}(2), 7.5 \mathrm{sec}$, and the $\mathrm{P}(3), 8.0 \mathrm{sec}$, were much reduced in comparison to those to the $\mathrm{U}(2), 13.7 \mathrm{sec}$, and the $\mathrm{U}(3), 13.0 \mathrm{sec}$, of the control series, respectively $(\mathrm{p}<0.01$ for both). This shows that the wasp which had oviposited into the unparasitized host only once could discriminate the parasitized from the unparasitized. The time of oviposition to the $P(1), 16.7 \mathrm{sec}$, was significantly shorter than that to the $\mathrm{U}(1)$ of both series 1 and 3 , $21.8 \mathrm{sec}$ and $21.0 \mathrm{sec}$, respectively $(\mathrm{p}<0.05$ for both). This suggests the innate a- 


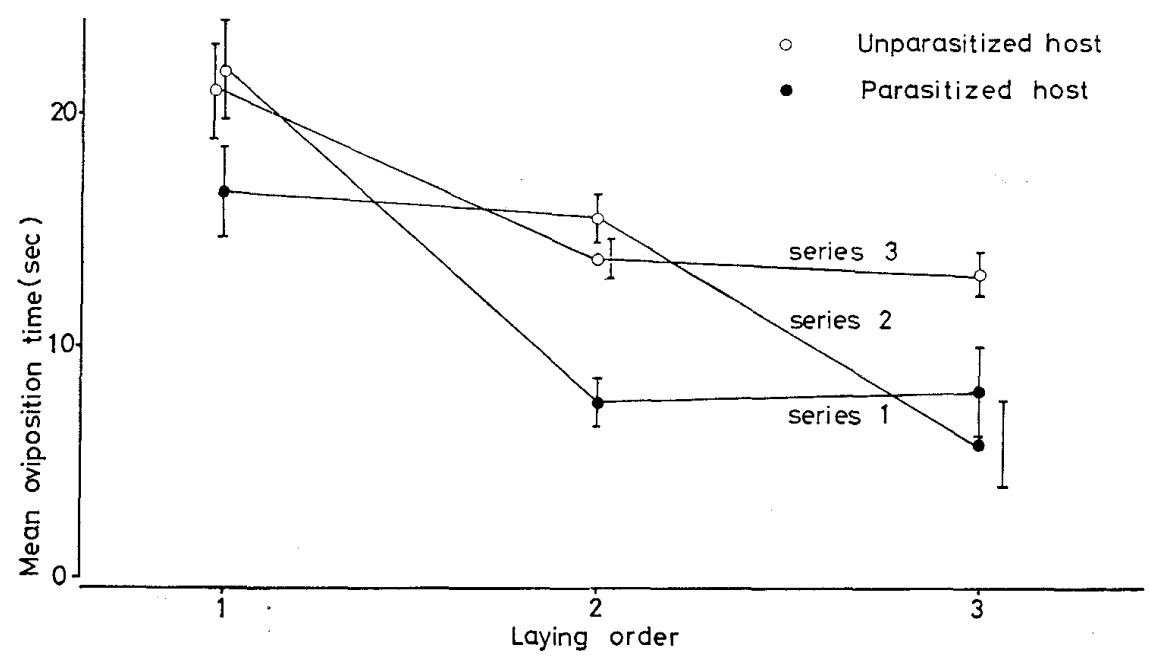

Fig. 3. Oviposition time with $95 \%$ confidence limits of the wasp to unparasitized and/or parasitized hosts successively offered.

Table 2. Oviposition time and number of eggs laid by inexperienced wasps

\begin{tabular}{ccc}
\hline Host & $\begin{array}{c}\text { Oviposition time } \\
(\mathrm{sec})\end{array}$ & No. of eggs laid \\
\hline Parasitized & $12.1 \pm 2.3^{\mathrm{a}}$ & $61.5 \pm 5.3^{\mathrm{b}}$ \\
Unparasitized & $17.4 \pm 2.0^{\mathrm{a}}$ & $34.8 \pm 2.7^{\mathrm{c}}$ \\
\hline
\end{tabular}

Values are means with $95 \%$ confidence limits.

a Significantly different at $1 \%$ level.

b,c Number of eggs laid in a host by two wasps(b), and by one wasp (c).

bility of the wasp to distinguish between a parasitized and unparasitized host. After parasitizing the $\mathrm{U}(2)$, the wasps of series 2 oviposited to the $\mathrm{P}(3)$ in significantly shorter time than those of series 3 did to the $\mathrm{U}(3)(\mathrm{p}<0.01)$. The reduction in oviposition time between that to the $\mathrm{P}(3), 5.7 \mathrm{sec}$, and to the $\mathrm{U}(3), 13.0 \mathrm{sec}$, was much greater than that between the $\mathrm{P}(1), 16.7 \mathrm{sec}$ and the $\mathrm{U}(1), 21.0 \mathrm{sec}$. It seems that the experience of having oviposited into the $\mathrm{U}(2)$ caused this greater reduction.

Another experiment was conducted to confirm the innate ability of the wasp in host discrimination. An unparasitized host was offered to an inexperienced wasp (the 1st wasp). This was replicated 32 times. Out of these once-parasitized hosts were randomly chosen 16, and a few hours after the 1st parasitization each one of them was parasitized again by another inexperienced wasp (the 2 nd wasp). All the larvae used for this experiment were dissected under the microscope to count the number of eggs laid in a host.

The oviposition time and number of eggs laid in a host are shown in Table 2. The mean time of oviposition to the once-parasitized hosts, $12.1 \mathrm{sec}$, was again significantly shorter than that to the unparasitized, $17.4 \mathrm{sec}(\mathrm{p}<0.01)$. The total number of eggs laid by both 1st and 2nd wasps, 61.5, was significantly smaller than the doubled number of eggs laid by the 1st wasp, $69.6(\mathrm{p}<0.05)$. Therefore it is considered that the 2 nd wasp laid less eggs to one parasitized host than the 1st wasp did to one unparasitized one. 


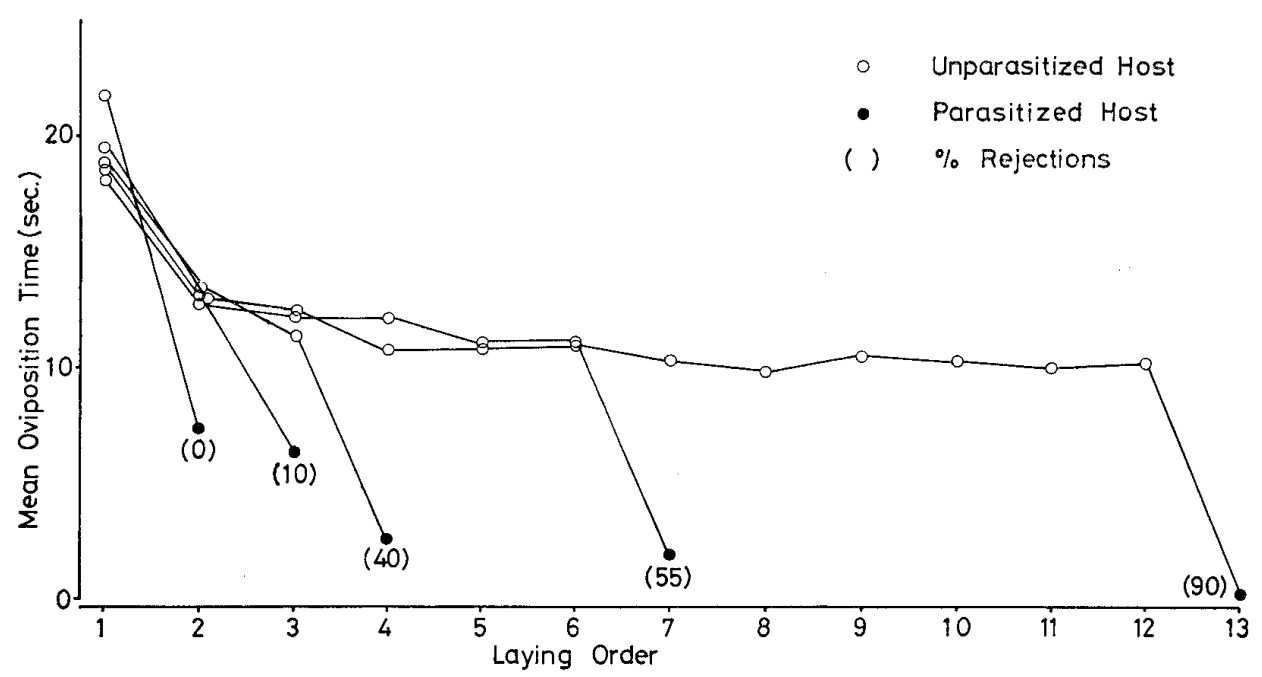

Fig. 4. Oviposition time of the wasp to either 1, 2, 3, 6 or 12 unparasitized hosts and a parasitized one successively offered at intervals of 1 minute.

\section{Oviposition to parasitized hosts by wasps with different experiences in oviposition}

In this experiment it was investigated how the frequency of oviposition by the wasp to an unparasitized host influenced her subsequent oviposition to a parasitized one. An inexperienced wasp was offered either 1, 2, 3, 6 or 12 unparasitized hosts and then a once-parasitized host at intervals of $1 \mathrm{~min}$. Each sequence was replicated 20 times. The wasps which drew their ovipositors out just after insertion were regarded to have rejected the hosts, and oviposition time was recorded as zero second.

As the frequency of oviposition to the unparasitized host increased, the time of oviposition to the parasitized host became shorter, from $7.5 \mathrm{sec}$ to $0.2 \mathrm{sec}$, and the percentage of rejections to the parasitized hosts increased from $0 \%$ to $90 \%$ (Fig. 4). The wasp may register the number of unparasitized hosts encountered, and calculate the expectancy of the next encounter; in another words, she can estimate their density. Based on this expectancy, she determines the parasitized hosts either to be accepted or rejected, and controls the number of eggs to be laid.

\section{DISGUSSION}

Many gregarious parasitoids have the ability to regulate the number of eggs and progeny sex ratio in a host according to host type. For example, Nasonia vitripennis decreases the number of eggs and increases the proportion of male progeny when she perceives a host to have been already parasitized (Wylie, 1966, 1973; Holmes, 1972). Suzuki and Iwasa (1980) reasoned this was because an individual female could adjust the sex ratio of her progeny to maximize her own inclusive fitness. Similarly, in the present study $A$. glomeratus could innately discriminate a parasitized from an unparasitized host (Table 2, Fig. 3), but she greatly changed the number of eggs laid in the former according to her previous experience in oviposition, as shown in Figs. 3 and 4. Moreover, even when the wasp oviposited only in unparasitized hosts, she changed the number of eggs laid according to her previous experience (Fig. 1). These results indicate that she could estimate the density of unparasitized hosts by the frequency of oviposition and controlled the number of eggs laid even in hosts of the same type 
and size. The results obtained and other phenomena known to date on the control of oviposition can be explained by the assumption that an individual wasp throughout her life behaves to maximize her genetic contribution to future generations.

Ovipositional experience of the wasp and her estimation of host density. First, we explain the fact that the degree of host discrimination varies according to the previous experiences of the wasp in oviposition. The reproductive success of an egg laid in a parasitized host is assumed to be smaller than that laid in an unparasitized host, irrespective of the total number of eggs laid in any single host. Since there are limitations on the expected life span of a wasp and the number of eggs produced throughout her life, it is best for her to oviposit only in unparasitized hosts, in cases where their density is high. On the contrary, when available unparasitized hosts are few, her best strategy is to oviposit both in parasitized and unparasitized hosts, even though the reproductive success of an egg laid in a parasitized host may be small. If the wasp can estimate the density of unparasitized hosts by, e.g., the mean interval of host finding during the period of host searching, then she may decide to oviposit or not based on the presumed density.

For example, a wasp which has never encountered any host long after her ovarian maturation may estimate the host density to be low. Thus, when such a wasp encounters a parasitized host she will oviposit in it, as was the case of $A$. glomeratus (Table 2, Fig. 3). The same explanation could be given to the phenomena that other inexperienced parasitoids accept their parasitized hosts (LENTEREN and BAKKeR, 1975; Lenteren, 1976; Klomp et al, 1980). This also explains why many parasitoids begin to oviposit in parasitized hosts when kept for long in a vial with only them (SALt, 1961).

Regulation of egg numbers to be laid in a host. We next consider the phenomena of a wasp changing the number of eggs even when she oviposits in hosts of the same type and size, in this case in unparasitized hosts of the same instar. The reproductive success of an egg laid in a host is a function of the total number of eggs in that host. In the gregarious parasitoids, this function may show an unimodal curve because excess eggs will cause higher mortality or smaller body size of their own by overcrowding, whereas fewer eggs will suffer higher mortality from, e.g., encapsulation (Kitano and Nakatsuji, 1978). When the host density is so high that the egg supply becomes limited, it is best for the wasp to lay the number of eggs which maximizes the reproductive success of each one. On the other hand, when the host density is so low that the egg supply is no longer limited, it is best to maximize the total reproductive success of the eggs laid in a host. The number of eggs the wasp will lay in each host will differ from that of the preceding high host density. The former egg number is usually larger than the latter (Suzuki, unpublished). Thus, the actual number of eggs laid in a host will fluctuate between these numbers according to presumed host density. This consideration explains the results given in Fig. 1, in which the number of eggs laid in a host by an inexperienced wasp was greatest at the 1st oviposition and then decreased gradually in successive ovipositions. This also explains the fact that the gregarious parasitoid, Caraphractus cinctus, when offered hosts at short intervals, reduced the number of eggs laid in each host (JAGKson, 1966). 


\section{AGKNOWLEDGEMENTS}

We are grateful to Associate Professor T. Ineshoji for his critical reading of the manuscript, and to Professor Y. Matsumoto and the colleagues of the Laboratory of Applied Entomology, University of Tokyo, for their kind help during the course of this study. We thank the members of the mathematical ecology group of the Department of Biophysics, Kyoto University, for their helpful discussions. We are also indebted to Mr. T. TANI of Kyoto Prefectural University for his offering of Pieris rapae crucivora.

\section{REFERENCES}

Holmes, B. H. (1972) Genetic evidence for fewer progeny and a higher percent males when Nasonia vitripennis oviposits in previously parasitized hosts. Entomophaga 17:79-88.

Jackson, D. J. (1966) Observations on the biology of Caraphractus cinctus Walker (Hymenoptera : Mymaridae), a parasitoid of the eggs of Dytiscidae (Coleoptera) III. The adult life and sex ratio. Trans. R. ent. Soc. Lond. $118: 23-49$.

Kitano, H. and N. Nakatsuji (1978) Resistance of Apanteles eggs to the haemocytic encapsulation by their habitual host, Pieris. J. Insect Physiol. 24 : 261-271.

Klomp, H., B. J. TeErink and W. G. MA (1980) Discrimination between parasitized and unparasitized hosts in the egg parasite Trichogramma embryophagum (Hym. : Trichogrammatidae) : a matter of learning and forgetting. Neth. J. Zool. $30: 254-277$.

Lenteren, J. G. van and K. Bakker (1975) Discrimination between parasitized and unparasitized hosts in the parasitic wasp Pseudeucoila bochei: a matter of learning. Nature 254:417-419.

Lenteren, J. C. van (1976) The development of host discrimination and the prevention of superparasitism in the parasite Pseudeucoila bochei WeLd. (Hym. : Gynipidae). Neth. J. Zool. 26 : 1-83.

Salt, G. (1934) Experimental studies in insect parasitism. II. Superparasitism. Proc. Roy. Soc. B, 114 : 455-476.

Salt, G. (1961) Competition among insect parasitoids. Symp. Soc. exp. Biol., XV, Mechanisms in Biological Competition, 96-119.

Suzuki, Y. and Y. Iwasa (1980) A sex ratio theory of gregarious parasitoids. Res. Popul. Ecol. 22 : 366382.

Wesloh, R. M. (1976) Discrimination between parasitized and nonparasitized hosts by the Gypsy moth larval parasitoid Apanteles melanoscelus. Can. Ent. $108: 395-400$.

Wylie, H. G. (1965) Some factors that reduce the reproductive rate of Nasonia vitripennis (WALK.) at high adult population densities. Can. Ent. $97: 970-977$.

Wylie, H. G. (1966) Some mechanisms that affect the sex ratio of Nasonia vitripennis (Walk.) (Hymenoptera : Pteromalidae) reared from superparasitized housefly pupae. Can. Ent. 98 : 645-653.

Wylie, H. G. (1970) Oviposition restraint of Nasonia vitripennis on hosts parasitized by other hymenopterous species. Can. Ent. $102: 886-894$.

Wylie, H. G. (1973) Control of egg fertilization by Nasonia vitripennis (Hymenoptera : Pteromalidae) when laying on parasitized house fly pupae. Can. Ent. $105: 709-718$. 